\title{
Researching Community and its Moral Projects
}

\author{
Les Back
}

\begin{abstract}
The study of community is a key area of concern in sociology and anthropology. In this paper it is argued that community should be understood as a moral project as well as a state of affairs or a set of social relationships. Through reviewing the current debate on the 'death of multiculturalism' the political and ethical dimensions of research practice are explored. The article argues for the development of a cosmopolitan method that reworks the relationship between technology, art and critical social science. Accounting for the complexities of community require a research imagination that is supple enough to attend to the interplay between local and global levels in order to find new ways of describing how people live in and across social divisions. Drawing on twenty years of research on the meanings of community in south London the paper explores the limits of interviewing and quantitative measures as they applied to social cohesion or social capital. It argues for a sensuous mode of scholarship in which the social relations of sound, smell, touch and taste can alert us to the ways in which community is inhabited and lived. The aspiration of this sensuous and multimodal agenda for researching community is to create vital forms of research that capture the conflicts as well as the opportunities that arise in city life.
\end{abstract}

Key words: community, multi-media, research, ethnography, 'death of multiculturalism', racism

\section{London's finished}

Charlie is the oldest surviving member of the fishmonger business that's been operating on Deptford High Street for three generations. ${ }^{1}$ He is 72 . Today, like every Saturday, he's at his stall cleaning and preparing fish. The fish that he sells don't come out of the sea, rather they come out of the sky. He says that each week a jet plane lands at Gatwick full of snappers, red fish, monkfish, and even flying fish that find their way to his stall and the others on the High Street. We talk for about half an hour while he cleans and de-scales the latest batch of

\footnotetext{
${ }^{1}$ The names of the research participants have been changed throughout to protect their anonymity. I would also like to thank and acknowledge Dawn Lyon as this material emerges from a collaborative visual ethnography of this market. Although any shortcomings in the discussion that follows are my own.
} 
imported produce. The fish scales collect on the floor like tiny thin shards of beaded glass. I asked him how long they'd been trading:

"About a 100 years. In the old days we had a pub next door. We had a fish fryer in the back and on Saturday nights when I was a boy the family used to serve battered fish to the customers from the pub. We're the only family run fishmongers left in London." I asked him if the young people in the family are learning the trade. "Yeah that's my son over there. He's keeping on the tradition but it's a different world now". Charlie's son is engaged to a Polish woman that he met in London, and he plans to move to Poland after they are married. Each night returning from the shop Charlie's son checks the exchange rate between the pound and the zloty and makes plans. I asked Charlie if the fish he sells now is different. "We used to be cod, haddock and plaice and skate. See now we sell to the people, the black and ethnic people and they don't want their fish filleted they want to buy their fish snappers and fish like that with the head on and eat with the head on as well. I don't sell to people like you (whites). You get a few of the old girls who are still 'ere and I give it away to them - won't take their money. When I was a kid if you saw a black person - used occasionally see one because of the docks down there [pointing in the direction of the river] - you'd follow them home - never seen anybody who looked like that. Now in the school at the end of the High Street you might see one or two white kids in a class - all blacks. It's a different world now - London's finished. London's finished. I don't know what my mother would say if she was alive. She wouldn't believe it. In her day people lived in very close ... it was all very local. People knew each other and invested in each other. Now they don't invest around here, they're sending their money to Africa and Pakistan. You see around here. The Pakis the people they've got working for 'em. You never see the same person in there twice, they're all illegal and they're paying 'em $£ 20$ a day. I am not joking you come back next weekend see if you recognise anyone else." Charlie no longer lives in Deptford; he moved out of London into the countryside of Kent. 
"It's too late to go back now but it's a different world. London's finished. I mean I love it around 'ere. I couldn't be anywhere else or doing anything else. But the world I knew and loved is gone forever. No point me getting undone about it, me getting undone isn't going to change it. It's too far gone; there is no going back now."

Community is a moral project. This has never been more apparent in the United Kingdom than in the recent discussions about diversity, community and social solidarity. The morality of community is implicit in Charlie's words although he never uses the term. How should researchers engage with such sentiments, how should we make sense of them? As Raymond Williams has pointed out such nostalgia for a lost 'golden age' recurs throughout history, it is a way of talking about social life providing a vocabulary for moral judgment that is situated in time (Williams 1973). Community talk can lament a world that has passed and/or invoke the possibility of new kind of world just on the horizon. The idea that London has been overwhelmed by diversity is not confined to the banter of market traders, it has become a pervasive idea, and without minimising the challenges of our current predicament, I want to question some of the terms of reference that are being used to both identify the nature of the problem and also the solutions that are being proposed to meet it. In short, how should researchers approach the investigation and understanding of community? What opportunities are there for researchers to re-imagine new modes and protocols of inquiring into community?

'Community studies' is a maligned sociological tradition. Ruth Glass once dismissed them as the "poor sociologist's substitute for a novel" (Glass (1989: 86). Others scoff at the parochialism of the genre and its limited horizon of mere local interest. To my mind the enduring contribution of community studies is its attention to situated descriptions of social life in process. These are never simply local matters. The enduring appeal has guided my own interest in the meanings of community in south east London that I have been researching for over twenty 
years using a range of techniques. Our understanding of community is inseparable from moral/ political controversies about nationhood belonging and this is even more the case in the wake of what has been called in Britain the 'death of multiculturalism'. What researchers notice and represent in their studies of community are increasingly drawn into moral and political controversies about the nature of a good society. My main line of argument is that community is not simply an organic fact or a straightforward state of affairs. This breaks with sociological treatment of community as a feeling of togetherness and mutual bonds or gemeinschaft that owes its origins to classical sociological theory (Tönnies 2001). In a globalised world such forms of togetherness take on radically new coordinates and relationships to place and time. This was brought home very pointedly in the story of a young person who contributed to a piece of research about community safety in East London. His landscape was one of global connectedness and local obstacles. While he speaks to his relatives in East Africa on the phone, and surfs the internet at night, he is afraid to go out of his front door for fear of racial attack (Räthzel 2008). The solidarities and exclusions within the 'community' no longer operate only through encounters that happen face-to-face. Additionally, the reality of community is enacted in the rhetoric of politicians and social researchers as much as it is argot of street traders. My first point is that there might be some merit in thinking of community as narrative achievement, a way of talking and telling life's story. It can make ways of acting possible, it can enable an opening up of the social landscape but it can also lead to a closing down of that landscape (Back 1996). An attention to how research itself gets enmeshed in the process of enacting community perhaps enables us to think about new and innovative ways of approaching the patterns of social life that the notion of community tries to name. Through reviewing recent controversies concerning the relationship between social solidarity and diversity this paper aims to identify the limits - both methodological and political - in the way researchers have attended to community. In the context of this special issue's concern with methodological innovation it also argues for developing new ways of recording and representing the global reach 
of local processes and community networks. Before addressing the issue of research practice I discuss the politicisation of the relationship between community and diversity.

\section{Hyper diversity and the "Death of multiculturalism"}

London is often described as amongst the world's 'hyper diverse cities'. In fact it is claimed that Britain's capital is the most culturally diverse city in the world with more languages spoken than in any other global city. Yet in the wake of the London bombings on $7^{\text {th }}$ July, 2005 public commentators routinely pronounce the death of multiculture in Britain (see Modood 2007), summed up in the idea that multiculturalism failed and that the advocates of a multicultural future were deluding themselves. William Pfaff writing in the pages of Britain's Observer newspaper claimed in the immediate aftermath of these tragic events that the young British men who blew themselves up killing people just like themselves were "monsters of our own making." ${ }^{2}$ The last decade and a half has seen perhaps the most intense phase of migration in Britain's history with some 2.3 million migrants, even more than in the mid twentieth century when colonial citizen migrants settled in Britain. The response amongst politicians has been to reanimate the language of assimilation, and the definition of Britishness has become a political project and a tool of statecraft. Citizenship is tested and social cohesion is calibrated. We might ask in this setting what does the idea of the 'death of multiculturalism' relate to if it does not relate to the evident fact of multiculture - albeit unruly and sometimes fractious - plain to anyone who strolls down Deptford High Street on a Saturday afternoon?

Crudely, it relates to Britain's inability to reckon with a metropolitan paradox, in which a city like London is both the stage for some of the most profound, and I would say beautiful, realisations of dialogue and radical multiculture; and yet, at the same time, it also provides an arena where brutal and enduring forms of

\footnotetext{
${ }^{2}$ William Pfaff “A monster of our own making” The Observer, 21st August, 2005
} 
racism take hold. Britain it seems cannot get over its past and racism holds the society hostage, as Paul Gilroy has described, the ire of hate is directed in our time of fear at the greater menace of the "half different and the partially familiar" (Gilroy 2004: 137). The conservative think tank Migration Watch argues that in recent polls $55 \%$ of Britons favour immigration control and $69 \%$ feel that Britain is "losing its culture." ${ }^{3}$ The language of 'culture loss' and passing of community in different ways seem to evoke a sense of insecurity. This insecurity is not a personal state but a battle to secure and defend society itself. This has taken on a new form in the midst of the scrutiny and mis-recognitions that result from the states of heightened alert in the midst of the 'threat of terrorism'.

Is social cohesion the answer? If a larger amount of social capital was banked in the community account would it fix the problem of our cities? I am not so sure. This is not to argue the merits of social attrition or rootlessness or an empty cosmopolitanism. As Jean Amery commented: "one must have a home in order not to need it" (Amery 1980: 46). I am mindful of those who are precisely struggling to make a home in the damaged landscapes of our cities. It is assumed in so much of the discourse about community that disorder, or lack of cohesiveness, is an inherent problem for society. Ralph Sampson argues that the issue of disorder becomes a societal obsession, be it in the famous 'Broken Window Theory' or the Victorian reformer's disgust with the poor keeping pigs in the street (Sampson 2008b). Controlling disorder is a vehicle for purifying or perfecting community. We have certainly seen this in relation to the responses of the Labour government to public concern after the $7^{\text {th }}$ July London bombings. But is a socially cohesive society always a good one? Charlie's portrait of homogeneous, localized, community sits poorly with my grandmother's stories of growing up in such communities in the 1930s. Her husband left the house one day and said he was going out to buy a "packet of fags" and never came back. The consequent suffocation and public shame she felt at being abandoned was

\footnotetext{
${ }^{3}$ MigrationWatchUK http://www.migrationwatchuk.com/outline_of_the_problem.asp
} 
palpable even to a twelve year old boy who listened to her talk for hours. She crossed the street to avoid looking into the faces of the members of this cosy and cohesive community. It bears saying that the gendered dimensions of community formations might be cohesive for some and imprisonment for others (Tonkiss 2005). Aren't there also huge hypocrisies to be found in the way the rich scramble for exclusive private school, gated worlds and riverside views? Setha Low's study of gated societies in the United States brings to life contradictions evident in such communities (Low 2004). Here the encounters with neighbours are limited and paradoxically the obsession with security systems and being 'safe' produce more fear in these introspective nano-communities. The shadow of threat is cast constantly across its ordered and clean architecture. These issues are no longer confined to the US suburbs and they are very much alive in British cities like London and social segregation is a central feature of Butler and Robson's account of middle-class life in the Capital (Butler and Robson 2003). It is striking that so much of riverside London's exclusive real estate seems entirely devoid of people.

\section{Immigrant/ Host Matrix}

Charlie is far from alone in his diagnosis that London is facing a crisis. Indeed, his voice could have very easily been amongst the many included in the Young Foundation's controversial study The New East End (Dench, Gavron and Young 2006). Michael Young was the author of Family and Kinship in East London with Peter Willmott, a classic of the community studies genre (Young and Willmott 1957). He died before this sequel was published and in a newspaper article his co-authors Geoff Dench and Kate Gavron summarized their argument as follows:

That simmering racial tension between the white working class and the large Bangladeshi community in Tower Hamlets has existed for more than 30 years is indisputable. But while conventional liberal opinion has tended to attribute its causes to white racism, the truth is more complex. The story 
of racial conflict in the East End is in part economic, part political, part historical. But what is most striking is the sense in which it is the direct, if unintended consequences of well-meaning welfare policy - particularly in the area of social housing allocation. ${ }^{4}$

The study provoked a controversy. Academic and former leader of Tower Hamlets council Michael Keith argued in the Guardian newspaper that the study confused nostalgia with history. ${ }^{5} \quad$ Elsewhere, the book has been subject to sustained sociological critique including a special issue of Sociological Research On-line dedicated to The New East End (Farrar 2008). A full account of this critique is beyond the terms of this article; rather I will focus on just two points. The first is methodological. Dench and Gavron want to give voice to the 'white working class', as a result they simply transcribe their speech as if what they say corresponds to a stable truth beyond the telling. The status of these accounts, the social resources they deploy are never questioned. These accounts might be better understood as a tangle of desires, resentments and grievances. The talk is taken to correspond to the truth of their condition. This misses the importance of trying to get beyond our dependence on language to pay attention not only to the work that the talk does but also what remains unsaid.

The second point is ontological and relates to the ways in which the account of community relies on 'white working-class' and the 'Bangladeshi community' as key categories. As John Clarke has pointed out the authors of the New East End set up ethnicity versus class. The white working class also absorbs a whole range of occupations that are not obviously working-class from taxi-drivers to publicans to bankers. At the same time, the Bangladeshi 'community' is not presented as being defined at all in relation to social class. Beneath this is a tacit hierarchy of belonging. The white working class are the East End's rightful heirs

\footnotetext{
${ }^{4}$ Dench, G. \& Gavron, K. 'Lost Horizons’ The Guardian, Wednesday February 82006

${ }^{5}$ Michael Keith "We should not confuse nostalgia with history' The Guardian Tuesday March 72006
} 
regardless of whether or not they actually still live in the East End. As Clarke comments: "By contrast, Bangladeshi migrants and their descendants appear to be history-less: they are in, but not of, the local community and cannot belong to this version of community" (Clarke, forthcoming: 24). This kind of thinking is held in place by the terms and frames of reference of what might be called the 'immigrant/host matrix' (Back 2007: 42). It endows some people with the homely privilege of automatic belonging, while others are always just passing through, whose presence is in some way in need of explanation. No surprise then that British National Party's house periodical Identity reviewed the New East End positively as "an important book." 6

Returning to riverside London south of the river the complexities of social class was one of the many extraordinary insights shown in Anthony Wonke's eight-part BBC documentary The Tower shown in 2007. The series told the story of the transformation of Aragon Tower - a former Greater London Council tower on Pepys Estate, Deptford - by Berkeley homes into prime riverside real estate and luxury flats. The geographical separation between the wealthy and the poor is achieved not just through establishment of gated communities but through the lifting of London's rich cosmopolites skyward. The new residents including Londoners of Cypriot and Iranian and Indian origin are presented ascending The Tower where they marvel not only at the view but also the stillness and quiet of life twenty floors up. Gated communities require the world outside to be held at the entrance on the ground floor, ensuring no unwanted noise disturbs their soundproofing. At the same time Deptford and its market is treated as the 'dodgy side'. Through the documentary film medium Wonke represents and brings to life the way new forms of distinction and division manifest in the housing market, cultural taste and public space. This is intensely about social class but it does not conform to ethnicised communities of fate or racial entitlement referred to so casually in the New East End. The ontology of racial difference is dangerous analytically and politically because it flattens or homogenises the economic

\footnotetext{
${ }^{6}$ Duncan Mayhew, 'The New East End', Identity, April 2007, pp.12-13
} 
interests and positions of people defined through such categories. Here these racial categories do little to explain or even describe the texture of multicultural landscapes as lived social arenas. These are not merely parochial issues confined to London or even the United Kingdom. The question of the relationship between diversity and social solidarity is now a key concern of influential American sociologists like Robert Putnam, the writer most associated with introducing the notion of social capital into academic discussion of community (Putnam, 2001; see also Fine 2001).

\section{Diversity and Social Solidarity}

In his recent work Robert Putnam focuses on the relationship between social capital, immigration and diversity (Putnam 2007). Drawn from the Social Capital Community Bench Mark Survey, a survey of 40,000 respondents in 41 US cities, the research argues trust in others and social solidarity is high in socially homogeneous settings. The social capital survey also corresponded with census data making it possible to correlate the calculation of social capital with the census data on race and ethnicity. Diversity - which Putnam defines very loosely - bundles together social markers of race, ethnicity, migration, culture, language, and religion. He argues that it is inversely correlated with social capital, and that diversity leads to social isolation for all groups including minority groups.

In the current climate of concern around issues of immigration and diversity Putnam's claims are challenging and contentious. In the context of the present discussion I want to make three critical points about this work. First, demography is not social formation or indeed community. We should know that not only from research methods textbooks, but from our lives - categories of persons might admit more diversity than they name shared sentiments, attributes or fates. Second, statistical surveys of this kind enact a certain kind of information but also conceal others. As Anthony Giddens has pointed out in his review of this study: 
"[Putnam's work] is based mainly on statistical correlations rather than actual local neigbourhoods. As he recognises, it has no time dimension. The next step is to look at specific areas as they change over time" (Giddens 2007: 88).

But the calculations in these types of macro analyses are locked within the assumption that social cohesion is always desirable, or that cohesion and social order are ideal states to which society should aspire. The use of such large statistical surveys can yield other kinds of facts and correlations. Robert Sampson in a study of violent crime in the United States has shown that immigration is inversely correlated with violent crime. In his examination of violent acts committed by close to 3,000 males and females in Chicago between the ages of 8 to 25, he found that there were fewer incidents of crime amongst the recently settled. Taken together higher rates of immigration actually lessened crime: "immigration and the increasing cultural diversity that accompanies it generates the sort of conflicts of culture that lead not to increased crime but nearly the opposite" (Sampson 2008a: 33). Mobile itinerant communities depicted here are less prone to illegality precisely because of their desire to integrate. One could extend this finding and hypothesize that it is the nature of the experience in the 'host society' that triggers illegality rather than crime being a 'foreign import.' The age of migration produces many paradoxes. 'Illegal immigrants' are often the most law abiding, desperate as many of them are to be unnoticed in the crowded city. As Sampson shows disorder or change can have effects that are counter-intuitive and that diversity, rather than being a problem, may even be a solution. 'Community breakdown' might offer opportunities as well as costs. Disorder or change need not induce melancholia or a sense that there is a deficit of community. This is a different kind of model of community which combines shared reference points but also a looseness in terms of how identity and belonging is scripted. I think it is here that we should look both to describe and to value what others like Paul Gilroy refer to as a convivial culture in which "a degree of differentiation can be combined with a large measure of overlapping" (Gilroy 2006: 28). Before anything else, we need 
to find more accurate ways to actually describe the complexities of how people actually live. The categories that we use to define and describe community do not seem to help much with this challenge; at best they are starting points at worst they are strait-jackets. What may indeed be of value in what Putnam and others mourn is precisely the opening up of a greater sense of inclusion as the normative centre of social solidarities that are defined through hierarchies of belonging start to shift.

\section{Complexities of Belonging and New Research Protocols for Community Studies}

The remarkable story that is seldom remarked upon is the way in which people within this diverse social fabric, regardless of the repeated pronouncements to the contrary, simply get along, acknowledge each other, live alongside each other intimately, and even learn to love each other. It seems that those who would argue for the embrace of multicultural future, and I am as culpable as anyone else, have failed both to name and to find an adequate language and method to describe such forms of sociality, its rhythms, ethos and shape and produce and adequate inventory of our current predicament. Like the fool who is thirsty amid an abundance of water, the fact of multiculture is all around us and yet it remains elusive. By contrast, the best documentary filmmakers are often much better at capturing the detail of these dynamics. This is explained partially by the ways film allows social life to be shown in process and visually.

Geoff Payne commenting on the limits of sociological writing concludes: "Community studies without pictures are like reading Shakespeare's plays, but never experiencing them in the theatre" (Payne 1996: 19). There is a long tradition of using photography and visual sociology in community studies (Crow 2002). Today researchers have more opportunities than ever before to use digital media to re-think the nature of social observation in a more multi-media and mobile form. For example, Andrew Clark and Nick Emmel have explored the 
methodological potential of using walking tours and ambulant interviews in order to access hidden dimensions of community life (Emmel and Clark (2007). Talja Blockland in a similar way used photography and walking tours to create new forms of knowledge about inner city Rotterdam (Blokland 2003). The point here is that through using multi-modality researchers develop a different kind of attentiveness to the embodied social world in motion. Not being limited to what people say explicitly enables us to train a kind of attentiveness to what remains unsaid and tacit forms of recognition and coexistence.

One thing that strikes me often is the way in which people give way to each other in the street, if you are coming up to a traffic light or a pedestrian crossing, the choreography of giving way and allowing space. Sometimes there is a struggle, a provocation. I sometimes look on bemused at the groups of young people mostly but not always young men - who insist on walking down the middle of the road and refuse to give way to cars. Through their action they state provocatively - "We are here even though we know we shouldn't be." These are exceptions, though, and only periodically interrupt the low level routines of acknowledgement and recognition. Ghassan Hage writes beautifully about such everyday negotiations with difference in his book Against Paranoid Nationalism (Hage 2003). In its final chapter he recounts a story concerning Ali who came to Australia as a refugee from Beirut, Lebanon. He suffered with shell shock and trauma from what he witnessed in Lebanon and the loved ones that he had lost. He developed a fondness for a pedestrian crossing in the suburb of Sydney where he lived. He would go there repeatedly and cross time and time again. "I loved the moment they stopped for me! It made me feel important" he told Ghassan Hage. "I thought it was magical. Could you imagine that happening in Beirut?" Ali did return to Beirut but his experience there in his own words "stripped him of his honour" (Hage 2003: 145). Of course, this is a fable. What Ghassan Hage does so brilliantly is help us make this small moment in a refugee's life speak to the complexities of migration, exile and belonging. I am not inviting some cross cultural comparison of road crossing but rather I think it 
does speak to the ordinary routines of recognition which operate outside of language and in actions. In order to admit these routines to sociological investigation it is necessary to develop ways of picturing them and describing their interactive rhythm and tempo. This involves developing ways of researching the sensuous and sensory dimensions of social experience and community life.

Alex Rhys-Taylor demonstrates heterogeneous movements of culture are registered in the spaces of everyday life through taste. He recounts the story of Marcia who lives in London but grew up in St Lucia. Marcia's taste for mangoes is the means through which she makes connections between her past and the sensorium of multicultural London. She is an epicure of the fruit and in a way the mango provides the link both to her memories of the past and her current relationships. The diasporic structures of taste and feeling that Marcia shares with such relish are interpreted by Rhys-Taylor as a productive and generous remembering. This is not just a Proustian nostalgia but also a means to make connections and establish a homely sense of place. As she strolls down Ridley Road market with her ethnographic companion she reveals that she prefers the Pakistani mangoes to the African ones available on the market. She eats them in the way she learnt as a child in the Caribbean and the market itself provides a place where Marcia is secure. Yet this generosity is "unrequited by culture at large" (Rhys-Taylor 2007: 8) that either makes these tastes 'foreign' or 'exotic'. By extension the challenge for researchers is to develop modes of attentiveness that can provide a hospitable place to record, measure and describe the gustatory nuances and tastes of the global in the local. It also involves developing a mode of painstaking sociological attention that can describe the social world within a wider range of sensory experiences to include smell, taste and texture (Rhys-Taylor 2008).

Returning to Deptford High Street and the traffic and exchanges in fish other kinds of co-presences and dependencies are revealed if we pay close enough 
attention. On the one hand, there is Charlie's interview account and the mourning of the passing of a Golden Age and racist melancholy. However, recording the soundscape of his stall and the exchanges that unfold in real time reveal other dimensions of this social world. Contained in these recordings are rituals of sociality and banter between Charlie and his African clients who come to buy the heads of giant snappers that are cut in quarters for fish stew. The good natured haggling over price, the deals cut and the recipes shared indicate not an urban catastrophe where social life has suffered a fatal blow by the profusion of diversity but a measure of homely co-existence. We could develop an inventory of multiculture just from this one street, map its interconnections to the Caribbean, Africa, Vietnam, China, Indian and Bangladeshi hinterlands. Suzanne Hall has done precisely this in a survey of independent shop owners on the Walworth Road, South-east London. "We learnt that of the 130-odd independent shops, there were over 20 different countries of origin amongst the proprietors, with no single place of origin predominating" (Hall 2008: 11). The threads of these heteroglot global connections are visualised through producing two parallel maps, one showing the Walworth Road and beneath another showing a map of the world.

This extraordinary experiment represents powerfully how London's social fabric is woven through global interconnections that are threaded through the local community. Such maps also need to plot the dissonances, the arguments, the difficulties as well as the proximities. In Deptford it would need to include the business and trade which Charlie continues to benefit from despite what he might say about the 'ethnic people'. On the $24^{\text {th }}$ January, 2009 he sold 500 lobsters in a single morning as the local Chinese and Vietnamese community prepared to celebrate Chinese New year where eating lobster is customary. Charlie's son will marry an 'immigrant' and the couple plan to begin their life together anew in Poland. The acts and routines of multicultural trade and cross cultural love run counter to the idea that Charlie's nostalgia for the world that has passed is the 
whole story. While his family business may not last much longer, London is far from finished.

In summary, I am arguing for a re-animation of the debate about sociology's relationship to power and racism. In order for researchers to avoid being racism's accomplice we must maintain a critical stance on how community is moralised and politicised. Equally, the categories through which community is named need to be interrogated for how they are implicated in ethnic and racial ontology which are historical creations rather than natural states of affairs. Also, I propose that the study of community should foster a wider range of ways of representing social life including photography, film, and sound recording. Everett Hughes once characterised sociology as the "science of the interview" (Hughes 1971: 507). I have argued that social research needs to reduce its over-reliance on interviews and embrace the opportunities to re-think its modes of observation and analysis. For researchers this means reducing our fascination with big stories and spectacular social problems. It also invites the challenge of developing an inventory of the elsewhere nearby and attending to the rhythms of recognition and undeclared coexistence while remaining vigilantly attentive to the damage racism does to them. This also foregrounds the importance of material culture in providing the traces of the past and elsewhere in the local and it requires paying attention to the matter of things and things that matter (see also Miller 2008). Such a cosmopolitan method reworks the relationship between technology, art and critical social science in order to use new media to recalibrate the relationship between observers and observed. It also means that the research imagination has to be supple enough to attend to the interplay between local and global levels in order to find new ways of describing how people live in and across the histories and futures that they make in the present. This also means research practice will not be limited by what is said or counted. Challenging the dominance of word and figure also invites the possibility of thinking research within the social relations of sound, smell, touch and taste. The ultimate aspiration of this sensuous and multimodal agenda for researching 
community is to create vital forms of research that can be faithful to the conflicts and the opportunities that arise in multicultural everyday life.

\section{Bibliography}

Amery, J. (1980) At the Mind's Limit: contemplations by a survivor on Auschwitz and its realities Bloomington and Indianapolis: Indiana University Press Back, L. (2007) The Art of Listening Oxford: Berg.

Back, L. (1996) New Ethnicities and Urban Culture: racisms and multiculture in young lives London: UCL Press

Butler, T. and Robson, G. (2003) London Calling: The Middle Classes and the Re-Making of Inner London Oxford: Berg

Clarke, J. (forthcoming) 'People and Places: the search for community' in G. Mooney and S.Neal (eds) Community: Crime, Welfare and Society Maidenhead: The Open University Press in association with The Open University, 2009.

Crow, G. (2002) 'Developing sociological arguments through community studies', International Journal of Social Research Methodology, 3(3): 173-87

Dench, G., Gavron, K., and Young, M. (2006) The New East End: Kinship, Race and Conflict London: The Young Foundation

Emmel, N. and Clark, A. (2007) 'We walk the walk, but can we talk the talk (with deference to John Lee Hooker): walkabouts to understand the lived environment of the community', Developing 'mobile' methods $12^{\text {th }}$ June 2007, Cardiff University at http://www.cardiff.ac.uk/socsi/qualiti/IntDisSem2007/rlmleeds.ppt. accessed January 2009

Farrar, M. (2008) 'Analysing London's 'New East End' - How Can Social Science Make A Difference?', Sociological Research Online, Volume 13, Issue 5, http://www. socresonline.org.uk/13/5/7.html

Fine, B. (2001) Social Capital versus Social Theory: Political Economy and Social Science at the Turn of the Millennium New York: Routledge Giddens, A. (2007) 'Doubting Diversity's Value,' Foreign Policy, Nov/ Dec: 87-88 
Gilroy, P. (2006) Multiculture in Times of War, Inaugural Lecture, London School of Economics, Wednesday $10^{\text {th }}$ May, 2006.

Gilroy, P. (2004) After Empire: Melancholia or Convivial Culture, London: Routeledge

Glass, R. (1966/1989) 'Conflict in Cities', reprinted in Clichés of Urban Doom and Other Essays Oxford: Basil Blackwell

Hage, G. (2003) Against Paranoid Nationalism: Searching for Hope in a Shrinking Society London: Merlin Press

Hall, S. (2008) 'Armed with Our Inexperience: A Survey of the Walworth Road,' Street Signs, Autumn: 10-11.

Hughes, E. (1971) The Sociological Eye: Selected Papers Chicago,IL, Aldine Atherton

Low, S. (2004) Behind the Gates: Life, Security, and the Pursuit of Happiness in Fortress America New York \& London: Routledge Massey, D. (1994) Space, Place and Gender Cambridge: Polity Press

Miller, D. (2008) The Comfort of Things Cambridge: Polity

Modood, T. (2007) 'Multiculturalism, citizenship and national identity,' Opendemocracy http://www.opendemocracy.net/faitheurope islam/multiculturalism 4627.jsp

Payne, G. (1996) 'Imagining the Community' in E. S. Lyon and J. Busfield (eds) Methodological Imaginations Basingstoke: Macmillan

Putnam, R. (2007) U Pluribus Unum: Diversity and community in the $21^{\text {st }}$ century - The 2006 Johan Skyette Prize Lecture, Scandinavian Political Studies, Vol 30, 2: $137-174$.

Putnam, R. (2001) Bowling Alone: the Collapse and Revival of American Community London: Simon \& Schuster

Räthzel, N. (2008) (ed.) Finding the Way Home: Young People's Stories of Gender, Ethnicity, Class, and Places in Hamburg and London Hamburg: Vandenhoeck and Ruprecht

Rhys-Taylor, A. (2007) 'The Irrepressibility of Mangifera' Eurozine http://www.eurozine.com/authors/rhystaylor.html 
Rhys-Taylor, A. (2008) 'Bear with me. I'm quite a quick walker but it's a long market,' Street Signs, Autumn: 20-21

Sampson, R. (2008a) 'Rethinking Crime and Immigration' Contexts 7:28-33

Sampson, R. (2008b) Disparity and Diversity in the Contemporary City: social

order revisited, British Journal of Sociology Annual Lecture, $21^{\text {st }}$ October, 2008, London School of Economics, London

Tonkiss, F. (2005) Space, the City and Social Theory. Cambridge: Polity.

Tönnies, F. (2001) Community and Civil Society New York: Cambridge University

Press

Williams, R. (1973) The Country and the City New York: Oxford University Press

Young, M. and Willmott, P. (1957) Family and Kinship in East London London:

Routledge \& Kegan Paul 